\title{
Anaesthetic management of xipho-omphalophagus seperation surgery: A case report
}

\author{
Bilal B*, Arslan M, Öksüz G, Gişi G, Boran ÖF and Öksüz H \\ Department of Anaesthesiaand Reanimation, Kahramanmaras Sutcu Imam University Faculty of Medicine, Turkey
}

\section{Introduction}

Conjoined twins is a rare congenital malformation, the incidence of conjoint twins varies 1:50.000 - 1:100.000. \%75 of the conjoint twins are female. Most of the conjoint twins are stillborn and one third of live births die within the first few days. Conjoint twins are classified according to the conjunction site of the body: thorax (thoracopagus) \%40, abdomen (xiphopagus and omphalopagus) $\% 30$, sacrum (pygopagus) $\% 18$, pelvis (ischiopagus) $\% 6$, craniopagus $\% 1-2$ [1-4]. Detailed evaluation of shared organs and associated anomalies is significant for anesthetic management. Conjoined twins usually presents with complex anatomical conjunction, multiple congenital anomalies, and different digrees of cross circulation. These conditions changes and complicates the preoperative evaluation, anesthetic management, airway management, and keeping up the hemodynamic stability. According to the congenital malformation, separation surgery must be performed by the multi-disciplinary team of physicians: anaesthesiologists, pediatric surgeons, cardiac surgeons, orthopaedic surgeons, urologists and specialists in reconstructive surgery.

The purpose of this case report was to share our anesthetic experience and review the anesthetic management strategies in conjoint twin separation surgeries.

\section{Case}

Gravida 3, Para 3, totally $4100 \mathrm{~g}$ female newborns delivered by caesereian section at the gestational week 38 in our hospital. In antenatal period the conjunction at xipho-omphalopagus was misdiagnosed, conjunction determined during the surgery. Xiphoomphalopagus was extending from the inferior border of the xiphoid process to the inferior border of the umblicus. All the other extremities was normal for each baby. The Apgar score was 5 at first minute and 8 at third minute for each baby. After monitorization and oxygenation of each neonate, the conjoint twins then admitted to the newborn intensive care unit (ICU) in our hospital. Preoperative examinations including haemogram, SGOT, SGPT, Na, K, BUN, creatinin was in normal range. Before the surgery all diagnostic radiological procedures like direct radiography, echocardigraphy, abdominal ultrasound was performed. Echocardiography did not demonstrate any cardiac anomalies, echocardiography revealed normal findings for each neonate. MRI showed minimal liver conjuction but there was no vascular connection. Abdominal ultrasound was not appropriate to assess the intraabdominal organs. Three days after delivery separation surgery planned. Two anaesthesia machines, two monitors, two anesthesia equipment kept ready for anesthesia procedure. To maintain homoeostasis of conjoined twins, the temperature of the operating room was set at $25-26^{\circ} \mathrm{C}$, a warming blanket was used and all fluids that administered to children were warmed. Children were placed on the operating table, no premedication was used. Intraoperative monitoring was including ECG, $\mathrm{SpO} 2$, etCO2, invasive arterial pressure via radial arteries, temperature and diuresis. To understand whether there is a common circulation; i.v. $0.1 \mathrm{mg}$ atropin administered to one on the right side(B) and then the other one on the left side (A) observed if there is tachycardya. After administration of atropin to B there was no increase in heart rate of A. General anaesthesia administered by two anaesthesiologists and four qualified anaesthesiological nurses. We used i.v. Na- Thiopental $5 \mathrm{mg} / \mathrm{kg}$ and fentanyl $1 \mu / \mathrm{kg}$ for anaesthesia induction for each baby. Firstly we intubated the baby on the left side (A) with 2.5 uncuffed endotracheal tube, after oscultating and proper placement of endotracheal tube we intubated the baby on the right side (B) with 2.5 uncuffed endotracheal tube. While positioning after intubating the twins, the endotracheal tube of the baby on the right side (B) dislodged. Then we reintubated the baby and secured the endotracheal tube. Maintenance of anaesthesia was provided with mixture of $\% 50$ oxygene $+\% 50$ air and $\% 2$ Sevoflurane. During the seperation surgery there was no extra haemorrhage, haemodynamyc parameters was in normal range for twins. Surgery lasted about 105 minutes. After surgery each twin extubated by one anaesthesia team separately. In postoperative period the twins transfered to the newborn intensive care unit (NICU).

\section{Discussion}

Management of a conjoint twin separation surgery is a multidisciplinary team approach that includes extensive medical examinations. For an anesthesiologist it may be an extraordinary professional experience. The major problem during anesthesia management is complexity in managing airway maintenance, the fact that in xipho-omphalopagus conjoined twins, heads facing each other handicap the maintenance of airway during anaesthesia induction $[5,6]$. In our patients during anesthesia induction we had a problem such as dislodging of the endotracheal tube. After dislodgement of the endotracheal tube we re-entubated the patient.

Other problems related to conjoint twins in anesthesia practice are dose adjustment of anesthetic drugs, effective and adequate lung ventilation, provide normothermia, positioning of conjoint twins on the operating table. The difficulty in these subjects is inability to weigh the exact mass of each twin. The anesthetic induction drugs used by

Correspondence to: Bilal B, Department of Anaesthesiaand Reanimation, Kahramanmaras Sutcu Imam University Faculty of Medicine, Turkey, Tel: 903443003245; E-mail: bilalbora@yahoo.com

Received: November 22, 2017; Accepted: December 08, 2017; Published: December 12, 2017 
predicting the approximate weight according to the relative size of each twin because there was no cross circulation each other $[7,8]$.

The most common coexisting congenital malformations reported in conjoint twins are genitourinary tract anomalies (19.8\%), the central nervous system malformations (18.9\%), and the musculoskeletal system anomalies (12.6\%), gastrointestinal atresias (9.9\%) and facial clefts $(9.9 \%)(1)$. The antenatal diagnosis of conjoined twins should set with ultrasonography (US) as early as 12 th gestational week gestation. More accurate evaluation of visceral conjunction is possible from 20 weeks gestation and should include fetal echocardiographic assesment. Additional advantage of the prenatal diagnosis of conjoint twins is that the planning of the place of delivery in an advanced and well equipped hospital [9]. In our patient, antenatal diagnosis of conjunction established during caesarian section. Absence of any organ or extremity anomalies may be a factor of underdiagnosis of conjunction. To avoid such situations, multiple pregnancies must be assessed with detailed ultrasound.

\section{References}

1. Mutchinik OM, Luna- Munoz L, Amar E, Bakker MK, Clementi M, et al. (2011) Conjoint twins: A worlwide collaborative epidemiological study of the International Clearinghouse for Birth Defects Surveillance and Research. Am J Med Genet C Semin Med Genet 157: 274-287. [Crossref]
2. Spitz L, Kiely EM (2003) Conjoined twins. JAMA 289: 1307-1310. [Crossref]

3. O'Neill JA Jr, Holcomb GW 3rd, Schnaufer L, Templeton JM Jr, Bishop HC, et al (1988) Surgical experience with thirteen conjoined twins. Ann Surg 208: 299-312. [Crossref]

4. Leelanukrom R, Somboonviboon W, Bunburaphong P, Kiatkungwanklai P (2004) Anaesthetic experiences in three sets of conjoined twins in King Chulalongkorn Memorial Hospital. Paediatr Anaesth 14: 176-183. [Crossref]

5. Szmuk P, Rabb MF, Curry B, Smith KJ, Lantin-Hermosoan MR (2006) Anaesthetic management of thoracopagus twins with complex cyanotic heart disease for cardiac assessment: special considerations related to ventilation and cross-circulation. $\mathrm{Br} \mathrm{J}$ Anaesth 96: 341-345. [Crossref]

6. Kobylarz K (2014) Anaesthesia of conjoined twins case series. Anaesthesiol Intensive Ther 46: 65-77. [Crossref]

7. Birmole B, Kulkarni B, Shah R (1993) Xipho- omphalopagous twins-separation in the newborn. J Postgrad Med 39: 99-101.

8. Thomas JM, Lopez JT (2004) Conjoined twins the anesthetic management of 15 sets from 1991-2002. Paediatr Anaesth 14: 117-129. [Crossref]

9. Kinston CA, Mc Hugh K, Kumaradevan J, Kiely EM, Spitz L (2001) Imaging in the preoperative assessment of conjoint twins. Radio Graphics 21: 1187-1208.

Copyright: $\mathbb{C} 2017$ Bilal B. This is an open-access article distributed under the terms of the Creative Commons Attribution License, which permits unrestricted use, distribution, and reproduction in any medium, provided the original author and source are credited. 